\title{
Brain Region-Specific Gene Expression Activation Required for Reconsolidation and Extinction of Contextual Fear Memory
}

\author{
Nori Mamiya, ${ }_{1}^{1}$ Hotaka Fukushima, ${ }^{1}$ Akinobu Suzuki, ${ }^{1}$ Zensai Matsuyama, ${ }^{1}$ Seiichi Homma, ${ }^{1}$ Paul W. Frankland, ${ }^{2}$ and \\ Satoshi Kida ${ }^{1,3}$ \\ ${ }^{1}$ Department of Bioscience, Faculty of Applied Bioscience, Tokyo University of Agriculture, Tokyo 156-8502, Japan, ${ }^{2}$ Program in Neurosciences and Mental \\ Health, Hospital for Sick Children Research Institute, Toronto, Ontario, Canada M5G 1X8, and ${ }^{3}$ Core Research for Evolutional Science and Technology, \\ Japan Science and Technology Agency, Saitama 332-0012, Japan
}

\begin{abstract}
During fear conditioning, animals learn an association between a previously neutral or conditioned stimulus (CS) and an aversive or unconditioned stimulus (US). Subsequent reexposure to the CS alone triggers two competing processes. Brief reexposure to the CS initiates reconsolidation processes that serve to stabilize or maintain the original CS-US memory. In contrast, more prolonged reexposure to the CS leads to the formation of an inhibitory extinction (CS-no US) memory. Previous studies have established that both reconsolidation and extinction require gene expression. Consistent with this, here we first show that genetic disruption of cAMPresponsive element-binding protein (CREB)-mediated transcription blocks both reconsolidation and long-term extinction of contextual fear memory. We next asked whether reconsolidation and extinction engage CREB-mediated transcription in distinct brain regions. Accordingly, we used immunohistochemical approaches to characterize the activation of the transcription factor CREB [as well as the expression of the CREB-dependent gene Arc (activity-regulated cytoskeleton-associated protein)] after brief versus prolonged reexposure to a previously conditioned context. After brief reexposure, we observed significant activation of CREB-mediated gene expression in the hippocampus and amygdala. In contrast, after the prolonged reexposure, we observed significant activation of CREB-mediated gene expression in the amygdala and prefrontal cortex. Finally, we showed that blocking protein synthesis in either the hippocampus or the amygdala blocked reconsolidation of contextual fear memory, whereas similar blockade in the amygdala and prefrontal cortex prevented the formation of extinction memory. These experiments establish that reactivated contextual fear memories undergo CREB-dependent reconsolidation or extinction in distinct brain regions.
\end{abstract}

Key words: reconsolidation; extinction; CREB; hippocampus; amygdala; mPFC

\section{Introduction}

To generate long-term memory, short-term memory undergoes a gene expression-dependent stabilization process known as memory consolidation (Flexner et al., 1965; Davis and Squire, 1984; McGaugh, 2000). Although it was previously thought that this consolidation occurs just once, there is growing evidence that memory retrieval is a dynamic process that can either reinforce or alter memory (Misanin et al., 1968; Schneider and Sherman, 1968; Lewis, 1979; Mactutus et al., 1979; Przybyslawski and Sara, 1997; Nader et al., 2000; Sara, 2000).

The fate of a retrieved memory appears to depend, in part, on the nature of the retrieval episode. In fear-conditioning para-

Received Sept. 26, 2008; revised Nov. 10, 2008; accepted Nov. 19, 2008.

S.K. was supported by Grants-in-Aid for Scientific Research, High Technology Research and Priority AreasMolecular Brain Science (18022038 and 22022039) from the Ministry of Education, Culture, Sports, Science, and Technology, Japan; by Core Research for Evolutional Science and Technology, Japan; and by the Research Grant for Nervous and Mental Disorders from the Ministry of Health, Labour, and Welfare, Japan.

Correspondence should be addressed to Satoshi Kida, Department of Bioscience, Faculty of Applied Bioscience, Tokyo University of Agriculture, 1-1-1 Sakuragaoka, Setagaya-ku, Tokyo 156-8502, Japan. E-mail: kida@nodai.ac.jp. DOI:10.1523/JNEUROSCI.4639-08.2009

Copyright $\odot 2009$ Society for Neuroscience $\quad$ 0270-6474/09/290402-12\$15.00/0 digms, for example, blocking protein synthesis before or immediately after brief reexposure to the conditioning stimulus (CS) alone disrupts the subsequent expression of the fear memory (Nader et al., 2000; Debiec et al., 2002; Kida et al., 2002; Suzuki et al., 2004). Such experiments have led to the idea that the reactivated fear memory is destabilized and then restabilized through a gene expression-dependent reconsolidation process (Nader et al., 2000; Taubenfeld et al., 2001; Debiec et al., 2002; Kida et al., 2002). In contrast, more prolonged reexposure to the CS leads to extinction of the fear memory (Pavlov, 1927; Rescorla, 2001; Myers and Davis, 2002). Similar to reconsolidation, this retrievalinitiated process appears to depend on new gene expression because blockade of protein synthesis before prolonged reexposure blocks the formation of an extinction memory [i.e., a new CS-no unconditioned stimulus (US) inhibitory memory that competes with the original CS-US memory trace] (Berman and Dudai, 2001; Vianna et al., 2001).

Together, these studies indicate that retrieval of a fear memory initiates two processes, reconsolidation and extinction, that have distinct temporal signatures (Eisenberg et al., 2003; Pedreira and Maldonado, 2003; Suzuki et al., 2004). Recent studies have also 
begun to suggest that these two processes are partially dissociable at the neurochemical level. For example, we showed that administration of either L-type voltage-gated calcium channels or CB1 receptor antagonists block extinction of contextual fear memory but have no effect on reconsolidation (Suzuki et al., 2004). In the current study, we ask whether reconsolidation and extinction are also dissociable at the anatomical level. We first showed that activation of cAMP-responsive element-binding protein (CREB)mediated transcription is necessary for both reconsolidation and long-term extinction of contextual fear memory. Next, we used immunohistochemical approaches to characterize the activation of the transcription factor CREB [as well as the expression of the CREB-dependent gene activity-regulated cytoskeletonassociated protein (Arc)] after brief versus prolonged context reexposure. After brief reexposure, we observed significant activation of CREB-mediated gene expression in the hippocampus and amygdala. In contrast, after the prolonged reexposure, we observed significant activation of CREB-mediated gene expression in the amygdala and prefrontal cortex. These results suggest that reconsolidation and extinction engage protein synthesisdependent processes in distinct brain regions. Consistent with this, we finally showed that blocking protein synthesis in either the hippocampus or amygdala blocked reconsolidation of contextual fear memory, whereas similar blockade in the amygdala and prefrontal cortex prevented the formation of extinction memory.

\section{Materials and Methods}

Mice. All experiments were conducted according to the Guide for the Care and Use of Laboratory Animals, Japan Neuroscience Society and the Guide for the Tokyo University of Agriculture. Male C57BL/6 mice were obtained from Charles River. Transgenic mice expressing an inducible CREB repressor (CREB ${ }^{\mathrm{IR}}$ mice) have been backcrossed to C57BL/6 (Kida et al., 2002; Suzuki et al., 2008). Mice were housed in cages of five or six, maintained on a $12 \mathrm{~h}$ light/dark cycle, and allowed ad libitum access to food and water. Mice were at least 8 weeks of age when tested. Testing was performed during the light phase of the cycle. All experiments were conducted blind to the treatment condition of the mouse.

Contextual fear conditioning test. Mice were trained and tested in conditioning chambers $(17.5 \times 17.5 \times 15 \mathrm{~cm})$ that had a stainless steel grid floor through which footshocks could be delivered (Suzuki et al., 2004, 2008). Training consisted of placing the mice in the chamber and delivering an unsignaled footshock ( $2 \mathrm{~s}$ duration, $0.4 \mathrm{~mA}$ ) $148 \mathrm{~s}$ later. Mice were returned to the homecage $30 \mathrm{~s}$ after the footshock (training).

For the first experiment, we examined the effects of disrupting CREB function on memory reconsolidation and extinction using transgenic mice that express an inducible CREB repressor $\left(\mathrm{CREB}^{\mathrm{IR}}\right)$ in the forebrain, where a dominant-negative CREB protein is fused with the ligand binding domain of a mutant estrogen receptor (ER). Previous studies have shown that systemic injection of tamoxifen, the artificial ligand for $E R$, into these transgenic mice inhibits CREB activity in the forebrain (Kida et al., 2002). Twenty-four hours after the training session, CREB ${ }^{\mathrm{IR}}$ and wild-type (WT) mice were placed back in the training context for 3 or $30 \mathrm{~min}$, during which time freezing behavior was assessed (reexposure) as the percentage of time mice spent freezing (defined as a complete lack of movement, except for respiration). Mice were administered an intraperitoneal injection of $16 \mathrm{mg} / \mathrm{kg}$ 4-hydroxytamoxifen (TAM; Sigma), which was dissolved in $10 \mathrm{ml}$ of peanut oil (Sigma) or vehicle (VEH; a similar volume of peanut oil) $6 \mathrm{~h}$ before the reexposure (Kida et al., 2002). Twenty-four hours after the reexposure session, mice were once again placed in the training context $(5 \mathrm{~min})$, and freezing behavior was assessed (test). Freezing behavior was measured automatically (O’Hara \& Co.) (Anagnostaras et al., 2001).

For the second experiment (phosphorylated and total CREB immunocytochemistry), we examined the brain regions that are activated after reexposure to the CS (see Fig. 2). Before the commencement of contex- tual fear conditioning, mice were handled individually for 2 min each day for 1 week. Mice were divided into eight groups: (1) Recon-33 and -60, and Ext-33 and -60 groups; four (conditioned) groups of mice were trained as described above and $24 \mathrm{~h}$ later were reexposed to the context for either $3 \mathrm{~min}$ (Recon groups) or $30 \mathrm{~min}$ (Ext groups). The animals were then anesthetized with Nembutal $(750 \mathrm{mg} / \mathrm{kg}$, i.p.) $3 \mathrm{~min}$ (Ext-33), 30 min (Recon-33, Ext-60), or 57 min (Recon-60) after the reexposure; (2) no US-33 and -60 groups; two (unconditioned) groups received a training session in the absence of footshock and $24 \mathrm{~h}$ later were reexposed to the context for either $3 \mathrm{~min}$ (no US-33) or $30 \mathrm{~min}$ (no US-60). The animals were then anesthetized, as above, $30 \mathrm{~min}$ after reexposure; and (3) no association-33 and -60 groups; the other two (unconditioned) groups were delivered a footshock $5 \mathrm{~h}$ after being placed in the conditioned chamber and returned to the homecage $30 \mathrm{~s}$ after the footshock. Twenty-four hours later, mice were reexposed to the context for either 3 $\mathrm{min}$ (no association-33) or $30 \mathrm{~min}$ (no association-60) and anesthetized, as above, $30 \mathrm{~min}$ after the reexposure. It is important to note that, in this experiment, the total length of time from the beginning of the reexposure to the anesthetization is $33 \mathrm{~min}$ (Recon-33, Ext-33, no US-33, no association-33) or 60 min (Recon-60, Ext-60, no US-60, no association$60)$. The Ext- 33 and Recon- 60 groups were used to compare the effects of the duration of reexposure on CREB activation with the Recon-33 and Ext-60 groups, respectively, using the identical time course from the beginning of the reexposure.

For the third experiment (Arc immunocytochemistry), mice were trained as above in the presence or absence of a footshock and $24 \mathrm{~h}$ later were reexposed to the context for 3 or $30 \mathrm{~min}$. The animals were anesthetized $90 \mathrm{~min}$ after the reexposure.

For the fourth experiment, we examined the effects of inhibition of protein synthesis in the medial prefrontal cortex (mPFC), hippocampus, and amygdala on memory reconsolidation and extinction. A protein synthesis inhibitor, anisomycin (ANI; Sigma), was dissolved in VEH solution, containing 3 drops of Tween 80 in $2.5 \mathrm{ml}$ of $7.5 \%$ dimethylsulfoxide in artificial CSF, and adjusted to $\mathrm{pH} 7.4$ with $\mathrm{NaOH}$. Mice were trained as above and $24 \mathrm{~h}$ later received intracranial injections of ANI $(62.5 \mu \mathrm{g})$ immediately after the reexposure phase of 3 or $30 \mathrm{~min}$. Twentyfour hours after the reexposure session, mice were once again placed in the training context ( $5 \mathrm{~min}$ ), and freezing behavior was assessed. Infusions into each brain region $(0.5 \mu \mathrm{l})$ were made at a rate of $0.25 \mu \mathrm{l} / \mathrm{min}$. The injection cannula was left in place for $2 \mathrm{~min}$ after the infusion. This dose of locally infused ANI inhibits $>90 \%$ of protein synthesis for at least $4 \mathrm{~h}$ (Rosenblum et al., 1993).

Immunocytochemistry. After the anesthetization, mice were perfused with $\mathrm{PBS} / 0.1 \mathrm{~mm}$ sodium fluoride $(\mathrm{NaF})$ containing $4 \%$ paraformaldehyde. Brains were then removed, fixed overnight, transferred to $30 \%$ sucrose, and stored at $4^{\circ} \mathrm{C}$. Coronal sections $(30 \mu \mathrm{m})$ were cut on a cryostat. After cutting the brain, sections were washed and preincubated in $3 \% \mathrm{H}_{2} \mathrm{O}_{2}$ in methanol for $1 \mathrm{~h}$, followed by incubation in blocking solution (PBS/0.1 mm NaF plus $1 \%$ goat serum albumin, $1 \mathrm{mg} / \mathrm{ml} \mathrm{BSA}$, and $0.05 \%$ Triton X-100) for $3 \mathrm{~h}$. Consecutive sections were incubated with a polyclonal rabbit primary antibody for anti-phospho-CREB (S133; 1:1000; Upstate Biotechnology), anti-CREB (1:1000; Upstate Biotechnology), or anti-Arc (1:1000; Santa Cruz Biotechnology) in the blocking solution overnight. To measure CREB activation, consecutive sections were alternately incubated with anti-phospho-CREB or antiCREB antibodies. Subsequently, sections were washed with PBS/0.1 mM $\mathrm{NaF}$ and incubated for $3 \mathrm{~h}$ at room temperature with biotinylated goat anti-rabbit IgG (SAB-PO kit; Nichirei Biosciences), followed by $1 \mathrm{~h}$ at room temperature in the streptavidin-biotin-peroxidase complex (SAB-PO kit). Structures were anatomically defined according to the atlas of Franklin and Paxinos (1997). Quantification of phosphorylated CREB (pCREB)-, CREB-, or Arc-positive cells in sections $(100 \times 100$ $\mu \mathrm{m}$ ) of mPFC (bregma between 2.10 and $1.98 \mathrm{~mm}$ ), amygdala (bregma between -1.22 and $-1.34 \mathrm{~mm}$ ), and dorsal hippocampus (bregma between -1.46 and $-1.82 \mathrm{~mm}$ ) was analyzed with a computerized image analysis system, as described previously (Winroof version 5.5 software; Mitani Corporation) (Frankland et al., 2006; Suzuki et al., 2008). Immunoreactive neurons were counted bilaterally with a fixed sample window 
across at least three sections by an experimenter blind to the treatment condition.

CREB activation (relative pCREB/CREB levels) was calculated by normalizing the number of pCREB-positive cells to the total number of CREB-positive cells. Data of pCREB/CREB levels and Arc expression for each group were expressed as a percentage of the averaged values in the no US-33 control group (Kee et al., 2007).

Surgery for microinfusion of drug. Surgeries were performed as described previously (Frankland et al., 2006; Suzuki et al., 2008). Under Nembutal anesthesia and using standard stereotaxic procedures, stainless steel guide cannulae (22 gauge) were implanted into the $\operatorname{mPFC}(2.7 \mathrm{~mm}, \pm 0 \mathrm{~mm},-1.6 \mathrm{~mm})$, the dorsal hippocampus $(-1.8 \mathrm{~mm}, \pm 1.8 \mathrm{~mm},-1.9$ $\mathrm{mm})$, or amygdala $(-1.3 \mathrm{~mm}, \pm 3.3 \mathrm{~mm},-4.4$ $\mathrm{mm})$. Mice were allowed to recover for at least 1 week after surgery. After this, they were handled for 1 week before the commencement of contextual fear conditioning.

Data analysis. Data were analyzed with ANOVA. One-way and post hoc NewmanKeuls comparisons were used to analyze the effects of treatments, drugs, and genotypes on freezing responses. One- or two-way ANOVA followed by post hoc Newman-Keuls and post hoc Bonferroni's comparisons, respectively, were used to analyze the effects of groups, times, and reexposure on CREB activation and Arc expression. Planned comparisons using a paired $t$ test were used to analyze the differences of freezing scores from the contextual conditioning of each group between the first $5 \mathrm{~min}$ reexposure, during the $30 \mathrm{~min}$ reexposure, and test. Comparisons of within-session extinction using a paired $t$ test and repeated ANOVA were used to analyze the effects of drug and genotype (Suzuki et al., 2004, 2008). All values in the text and figure legends are means \pm SEM.

\section{Results}

The relationship between reconsolidation and extinction of fear memory has been investigated (Eisenberg et al., 2003; Pedreira and Maldonado, 2003; Suzuki et al., 2004). Our previous study demonstrated that inhibition of protein synthesis after a short reexposure $(3$ $\mathrm{min}$ ) to the context disrupts the reactivated contextual fear memory, whereas a prolonged reexposure $(30 \mathrm{~min})$ followed by inhibition of protein synthesis blocked long-term extinction without disrupting the fear memory (Suzuki et al., 2004). These observations indicate that short and long reexposure triggers reconsolidation or extinction phases, respectively. In this study, to ask whether reconsolidation and extinction phases are dissociable at the anatomical level, we investigated brain regions regulating the reconsolidation and extinction phases.

\section{Roles of CREB-mediated transcription in reconsolidation and extinction}

Previous studies have shown that CREB-mediated transcription is required for the consolidation and reconsolidation of contextual fear memory (Kida et al., 2002). However, little is known about whether transcriptional activation by CREB is required for memory extinction. Therefore, we first examined the roles of CREB-mediated transcription in the reconsolidation and extinc-

E WT/VEH, WT/TAM, and CREB IR/VEH.
B

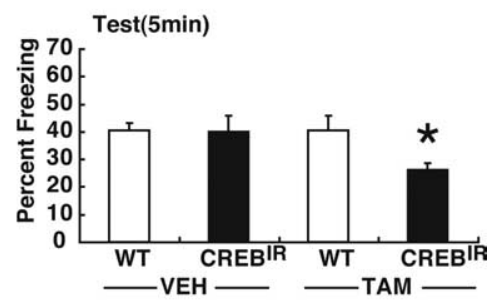

D

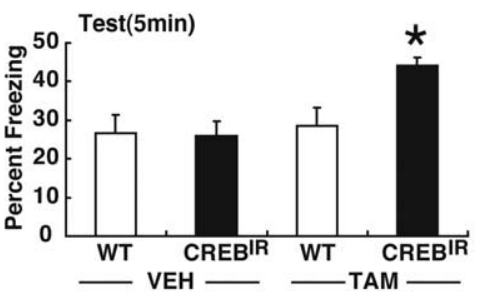

Figure 1. Effects of disrupting CREB function on memory reconsolidation and extinction. $A, C$, Experimental design used with (WT/VEH, $n=13$; CREB IR $/$ VEH, $n=11$; WT/TAM, $n=13$; CREB IR $/$ TAM, $n=11$ ). $\boldsymbol{B}$, Freezing score during test session. $\boldsymbol{C}, \boldsymbol{D}$, Effects of disrupting CREB function on extinction. C, Freezing score in $5 \mathrm{~min}$ blocks during $30 \mathrm{~min}$ reexposure (WT/VEH, $n=12$ the relationship between the duration of reexposure and freezing score at test session $(\boldsymbol{B}, \boldsymbol{D})$. Error bars are $S E M$. ${ }^{*} p<0.05$, versus

tion of contextual fear memory and then tried to investigate the brain regions where CREB is activated in the reconsolidation and extinction phases.

To examine the effects of loss of function of CREB on reconsolidation and extinction, we used CREB ${ }^{\mathrm{IR}}$ transgenic mice (Kida et al., 2002). In these experiments, $\mathrm{CREB}^{\mathrm{IR}}$ and WT littermate controls were trained with a single footshock and $24 \mathrm{~h}$ later were reexposed to the context for 3 or $30 \mathrm{~min}$. Six hours before the reexposure, mice received a systemic injection of TAM or VEH to induce the inhibition of CREB activity (Kida et al., 2002).

In the reconsolidation experiment, all groups showed comparable levels of freezing during the $3 \mathrm{~min}$ reexposure (Fig. 1A) $\left(F_{(3,44)}=0.15 ; p>0.05\right)$. When the contextual fear memory was tested $24 \mathrm{~h}$ later, one-way ANOVA revealed a significant effect of group (Fig. $1 B)\left(F_{(3,44)}=2.83 ; p<0.05\right)$. The post hoc NewmanKeuls test showed that TAM-injected CREB ${ }^{\mathrm{IR}}$ mice significantly froze less compared with the other groups (Fig. $1 B)(p<0.05)$. Consistent with previous observations, inhibition of CREB activity disrupted the reactivated fear memory, indicating that the 


\section{Day1 \\ Day2}

Recon-33

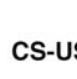

Recon-60

cs-us

no US-33

CS

no association-33

\section{CS-US}

(CS $5 \mathrm{hr}$ )
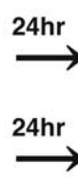

.
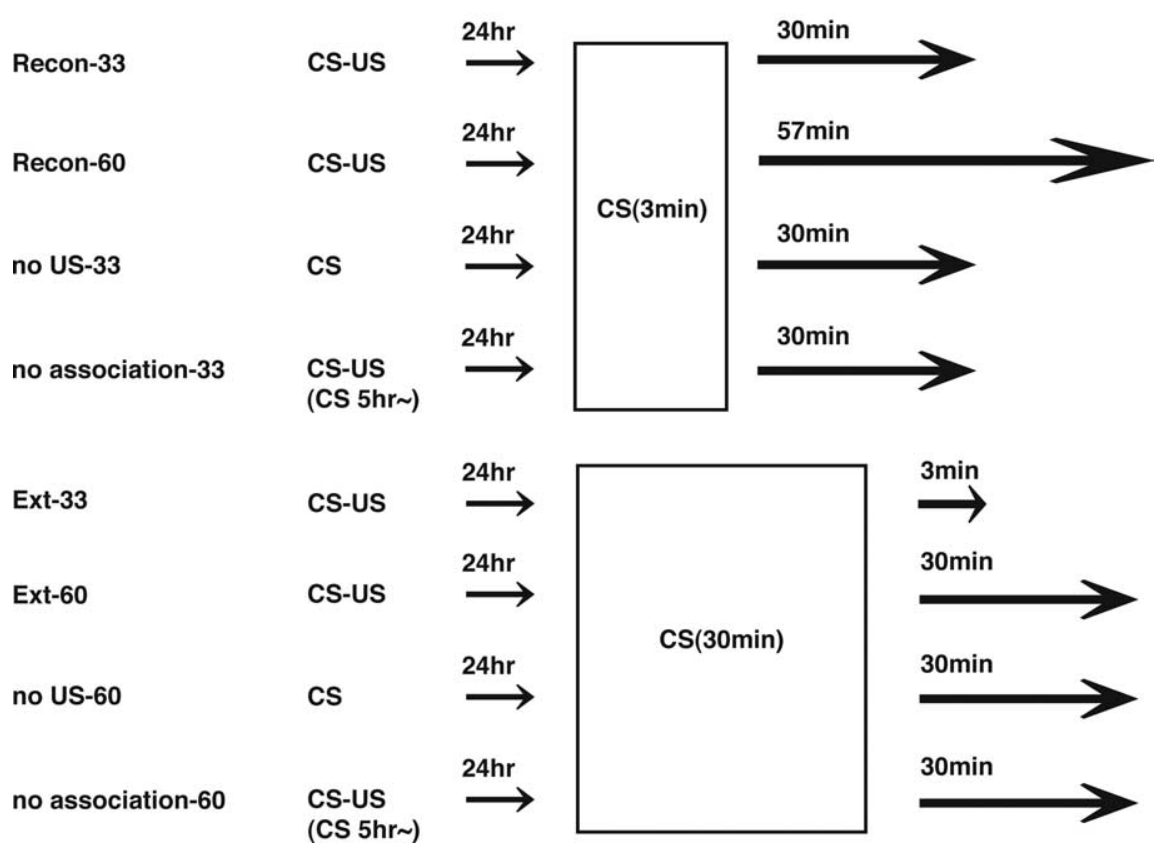

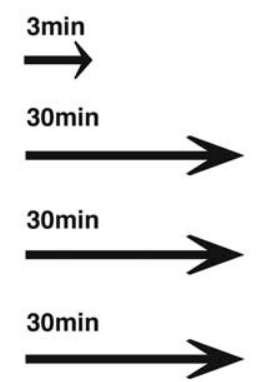

Figure 2. Experimental design. The experimental design to investigate changes in CREB activation in $\mathrm{MPFC}$, hippocampus, and amygdala induced by reconsolidation or extinction phases is shown.

contextual fear memory requires CREB-dependent memory for reconsolidation (Kida et al., 2002; Suzuki et al., 2008).

We next examined the effects of disrupting CREB function on memory extinction. Overall freezing levels did not differ across groups during the $30 \mathrm{~min}$ reexposure $\left(F_{(3,52)}=2.42 ; p>0.05\right)$ but did decrease over time in all groups $\left(F_{(5,260)}=74.2 ; p<0.05\right)$ (Fig. 1C). Measurements $24 \mathrm{~h}$ after this $30 \mathrm{~min}$ reexposure confirmed that the extinction of conditioned freezing was persistent in VEH-treated WT mice (first $5 \mathrm{~min}$ in the reexposure session vs test; $\left.t_{(22)}=3.03 ; p<0.05\right)$, indicating that long-term extinction occurred in these experimental conditions. In contrast, extinction tested $24 \mathrm{~h}$ after the $30 \mathrm{~min}$ reexposure was blocked by the inhibition of CREB function. One-way ANOVA across four groups revealed a significant effect of group (Fig. $1 D)\left(F_{(3,52)}=\right.$ 5.32; $p<0.05)$. TAM-injected CREB ${ }^{\mathrm{IR}}$ mice showed significantly more freezing compared with the other groups (Fig. $1 D)(p<$ 0.05 ). Thus, these results indicate that CREB is required for longterm extinction.

The effects of blocking CREB function on memory reconsolidation and extinction are summarized in Figure $1 \mathrm{E}$. These results indicate that activation of CREB-mediated transcription is required for both reconsolidation and long-term extinction. It is worth noting that although genetic inhibition of CREB activity blocked the formation of the new extinction memory, it presumably had no effect on the expression of the original fear memory. This observation is consistent with previous findings using systemic injection of ANI (Suzuki et al., 2004, 2008) and (1) confirms that reconsolidation and extinction of contextual fear memory have distinct temporal signatures and (2) suggests that these two processes interact.

\section{CREB activation in distinct brain regions in reconsolidation} and extinction phases

The transcription factor CREB is activated through phosphorylation at serine 133 by CREB kinases such as protein kinase $A$ and calcium/calmodulin-dependent protein kinase IV (Shaywitz and Greenberg, 1999; Mayr and Montminy, 2001). This phosphorylation is an essential step in the activation of CREB-mediated transcription (Gonzalez and Montminy, 1989; Ginty et al., 1994; Bito et al., 1996; Silva et al., 1998). Therefore, phosphorylation of CREB at serine 133 has been used to identify brain regions activated in gene expression-dependent memory processes (Viola et al., 2000; Hall et al., 2001).

Therefore, to ask whether reconsolidation and extinction phases are dissociable at the anatomical level, we next performed immunohistochemical analysis to identify brain regions where CREB is activated in the reconsolidation and extinction phases. Reconsolidation of fear memory has been shown to be mediated by the amygdala (Nader et al., 2000; Duvarci and Nader, 2004; Tronel et al., 2005; Lee et al., 2006) and hippocampus (Debiec et al., 2002; Frankland et al., 2006; Suzuki et al., 2008). In contrast, extinction of the fear memory is thought to depend on the MPFC (Morgan et al., 1993; Morgan and LeDoux, 1995, 1999; Morrow et al., 1999; Quirk et al., 2000, 2006; Santini et al., 2004) and amygdala (Lee et al., 2001; Lu et al., 2001; Walker et al., 2002; Lee et al., 2006; Myers and Davis, 2007). From these findings, we focused our anatomical analyses on the $\mathrm{MPFC}$, amygdala, and hippocampus.

CREB activation was assessed as the ratio of pCREB to total CREB levels in four conditioned and four unconditioned groups (Fig. 2). The conditioned groups of mice were trained with a footshock and $24 \mathrm{~h}$ later were re-exposed to the context for $3 \mathrm{~min}$ (Recon groups) or $30 \mathrm{~min}$ (Ext groups). Recon groups were assessed for CREB activation $30 \mathrm{~min}$ (Recon-33 group) or $57 \mathrm{~min}$ (Recon-60 group) after the reexposure, whereas Ext groups were assessed for CREB activation $3 \mathrm{~min}$ (Ext-33 group) or $30 \mathrm{~min}$ (Ext-60 group) after the reexposure. Unconditioned groups were treated similarly, except either that they did not receive a footshock (no US groups) or that they stayed in the conditioned chamber for $5 \mathrm{~h}$ before receiving the footshock (no association groups) and were assessed for CREB activation $30 \mathrm{~min}$ after the reexposure for $3 \mathrm{~min}$ (no US-33 and no association-33 groups) or $30 \mathrm{~min}$ (no US-60 and no association-60 groups). It is important to note that the conditioned groups froze at equal levels during the $3 \mathrm{~min}$ reexposure and for the first $5 \mathrm{~min}$ of the $30 \mathrm{~min}$ reexposure (Recon-33, $56.4 \pm 5.2 \%$; Recon-60, $58.3 \pm 3.4 \%$; Ext-33, $57.6 \pm 4.5 \%$; Ext-60, 59.2 $\pm 4.1 \%$ ), indicating that the contextual fear memory was reactivated. Longer (30 $\mathrm{min}$ ) reexposure reduced freezing over time within the session in both the Ext-33 and Ext-60 groups (to $24.9 \pm 5.9$ and $25.1 \pm 3.1 \%$, respectively), indicating that within-session extinction occurred (overall freezing: $F_{(1.125)}=0.12$, $p>0.05$; decrease over time: $\left.F_{(5,125}=28.45, p<0.05\right)$. In contrast, the unconditioned groups showed significantly lower freezing during the $3 \mathrm{~min}$ and the first $3 \mathrm{~min}$ of the long reexposure compared with the conditioned groups (data not shown).

$m P F C$

We first analyzed CREB activation in the mPFC [including the prelimbic (PL) and infralimbic (IL) regions]. Our experiments 
A

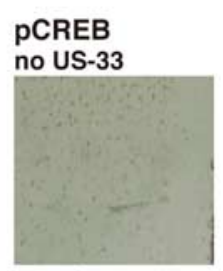

no US-60

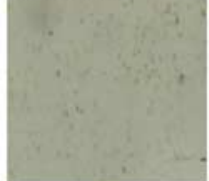

CREB

no US-33

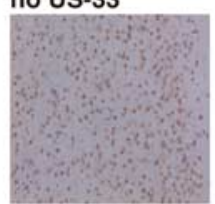

no US-33

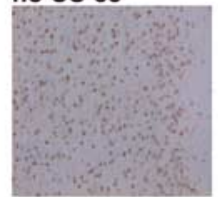

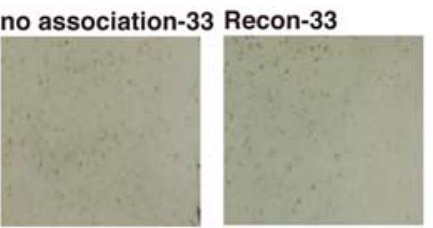

no association-33 Ext-33

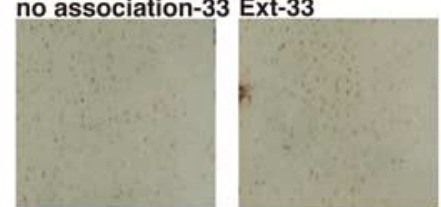

no association-33 Recon-33

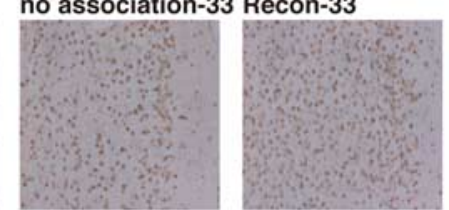

no association-60 Ext-33

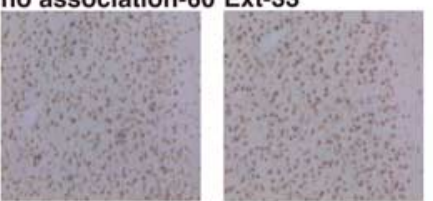

B

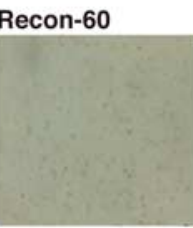

Ext-60

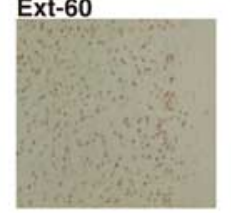

Recon-60

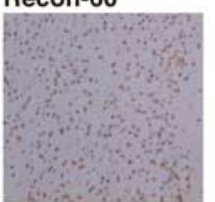

Ext-60

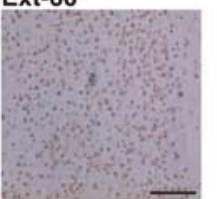

Prelimbic cortex

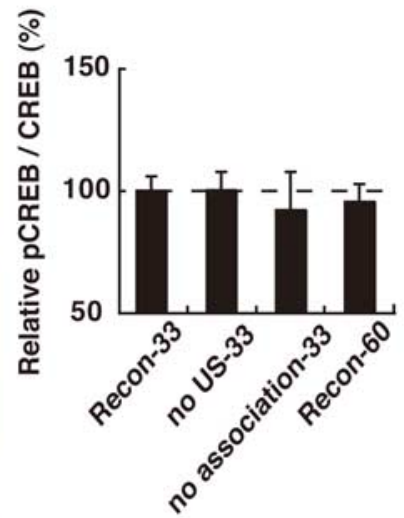

D Prelimbic cortex

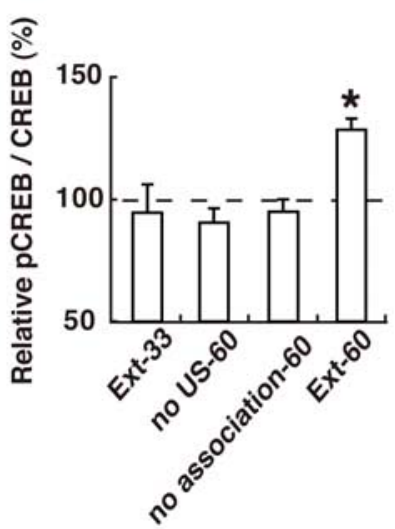

C

Infralimbic cortex

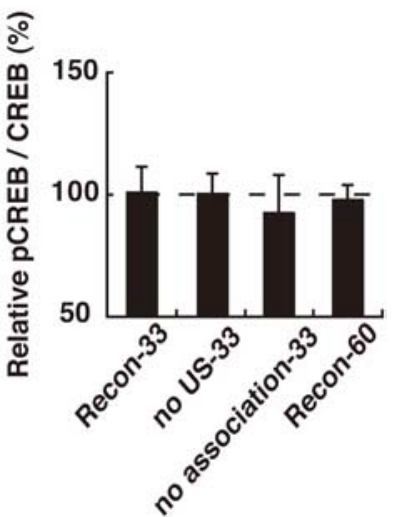

E Infralimbic cortex

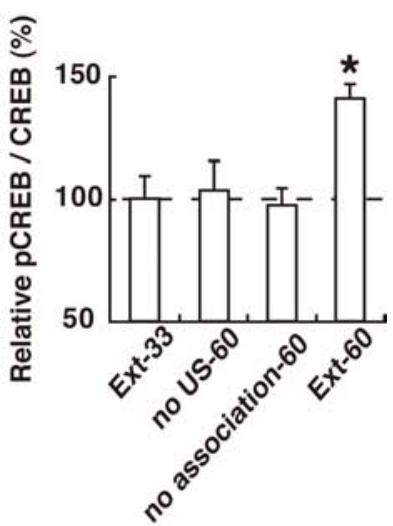

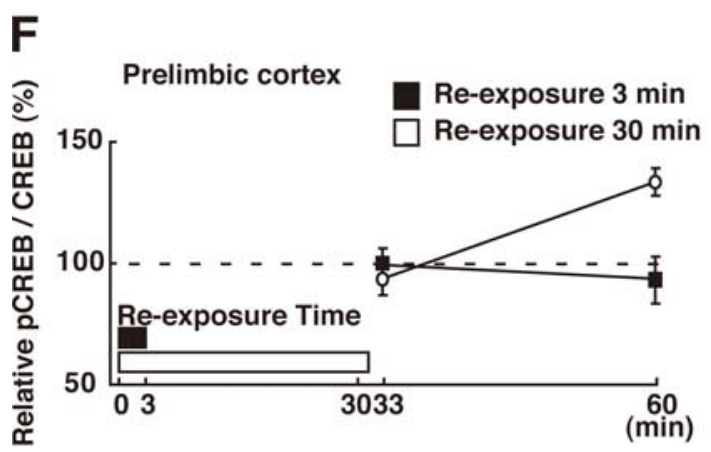

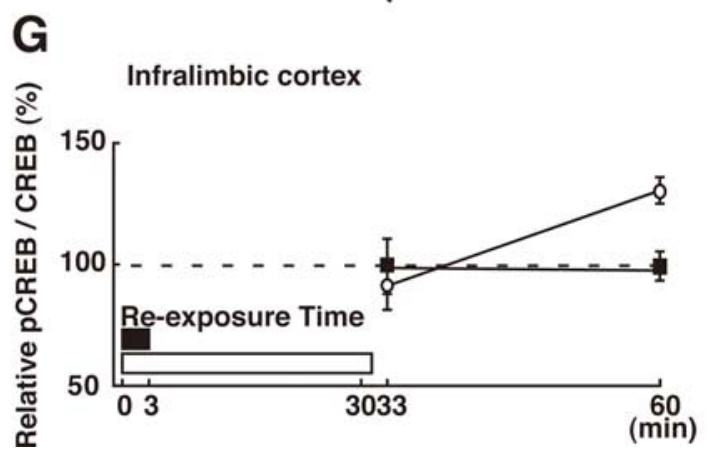

Figure 3. Effects of the reexposure duration on CREB activation in the mPFC. $A$, Representative PL pCREB-positive cell immunohistochemistry obtained from indicated mice. Scare bar, $100 \mu \mathrm{m}$. $\boldsymbol{B}, \boldsymbol{C}$, Effects of the 3 min reexposure duration on CREB activation in PL (B) and IL ( $($ ) regions of $\mathrm{mPFC}$ (Recon-33, $n=11 ;$ no US-33, $n=10$; no association-33, $n=9$; Recon-60, $n=9$ ). $\boldsymbol{D}, \boldsymbol{E}$, Effects of the 30 min reexposure duration on CREB activation in PL (D) and IL (E) regions of $\mathrm{mPFC}($ Ext-33, $n=10$; no US-60, $n=15$; no association-60, $n=14$; Ext-60, $n=17)$. ${ }^{*} p<0.05$, compared with the other groups. $\boldsymbol{F}, \mathbf{G}$, Comparison of CREB activation after 3 and 30 min reexposure in PL $(\boldsymbol{F})$ and IL $(\boldsymbol{G})$ regions of $\mathrm{mPFC}$ in the conditioned group. Error bars are SEM. CREB activation (relative $\mathrm{pCREB/CREB} \mathrm{levels)} \mathrm{was} \mathrm{calculated} \mathrm{by} \mathrm{normalizing} \mathrm{the} \mathrm{number} \mathrm{of} \mathrm{pCREB-positive} \mathrm{cells} \mathrm{to} \mathrm{the} \mathrm{total} \mathrm{CREB} \mathrm{positive} \mathrm{cells.} \mathrm{Data} \mathrm{of} \mathrm{CREB} \mathrm{activation} \mathrm{for} \mathrm{each} \mathrm{group} \mathrm{were} \mathrm{expressed} \mathrm{as} \mathrm{the} \mathrm{percentage} \mathrm{of} \mathrm{the}$ averaged values in the no US-33 control group.

revealed that $\mathrm{CREB}$ was activated in the extinction but not the reconsolidation phase. One-way ANOVA across the 3 min reexposure (reconsolidation) groups (Recon-33, Recon-60, no US33, and no association-33) revealed no significant effect of group in the PL and IL regions (PL: $F_{(3,35)}=0.17, p>0.05$, IL: $F_{(3,35)}=$ $0.12, p>0.05)$, indicating that CREB was not activated in either of these $\mathrm{mPFC}$ regions in the reconsolidation phase (Fig. $3 B, C$ ). In contrast, one-way ANOVA across the $30 \mathrm{~min}$ reexposure (extinction) groups (Ext-33, Ext-60, no US-60, and no association$60)$ revealed significant effects of group in the PL and IL regions (Fig. $3 D, E)\left(\right.$ PL: $F_{(3,52)}=5.99, p<0.05$; IL: $F_{(3,52)}=6.25, p<$
0.05). The post hoc Newman-Keuls test showed a significantly higher level of pCREB in both mPFC regions of the Ext-60 groups compared with the other groups (Fig. $3 D, E)(p<0.05)$. This result indicates that $\mathrm{CREB}$ was significantly activated in the PL and IL regions of the conditioned groups after the $30 \mathrm{~min}$, but not $3 \mathrm{~min}$, reexposure. We next compared the time course of CREB activation from the beginning of the reexposure (using the identical time schedule) among the conditioned groups (Recon-33, Recon-60, Ext-33, and Ext-60). Consistent with the above results, a two-way ANOVA with reexposure (3 vs $30 \mathrm{~min}$ ) and time (from the beginning of reexposure; 33 vs $60 \mathrm{~min}$ ) revealed significant 

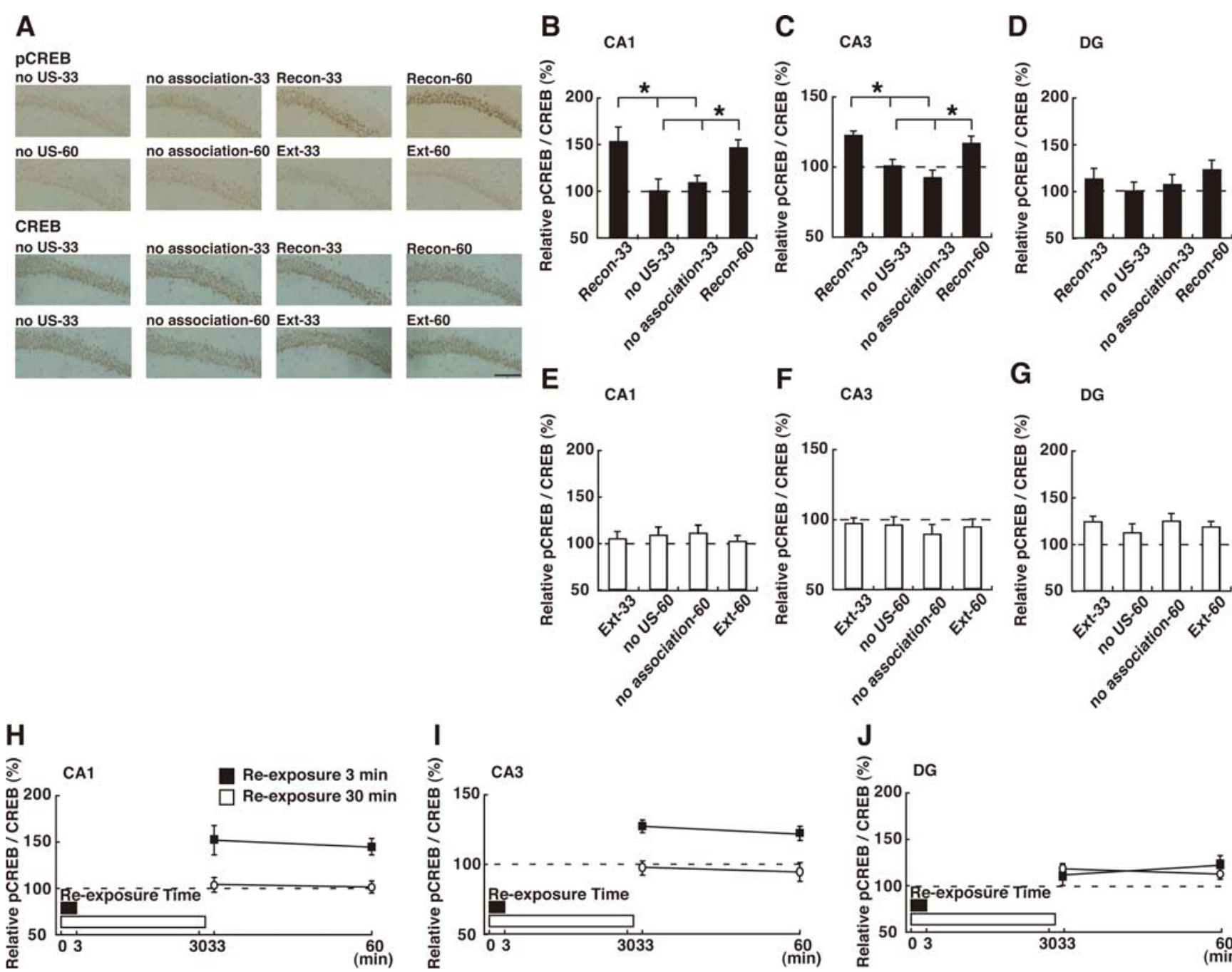

CA3
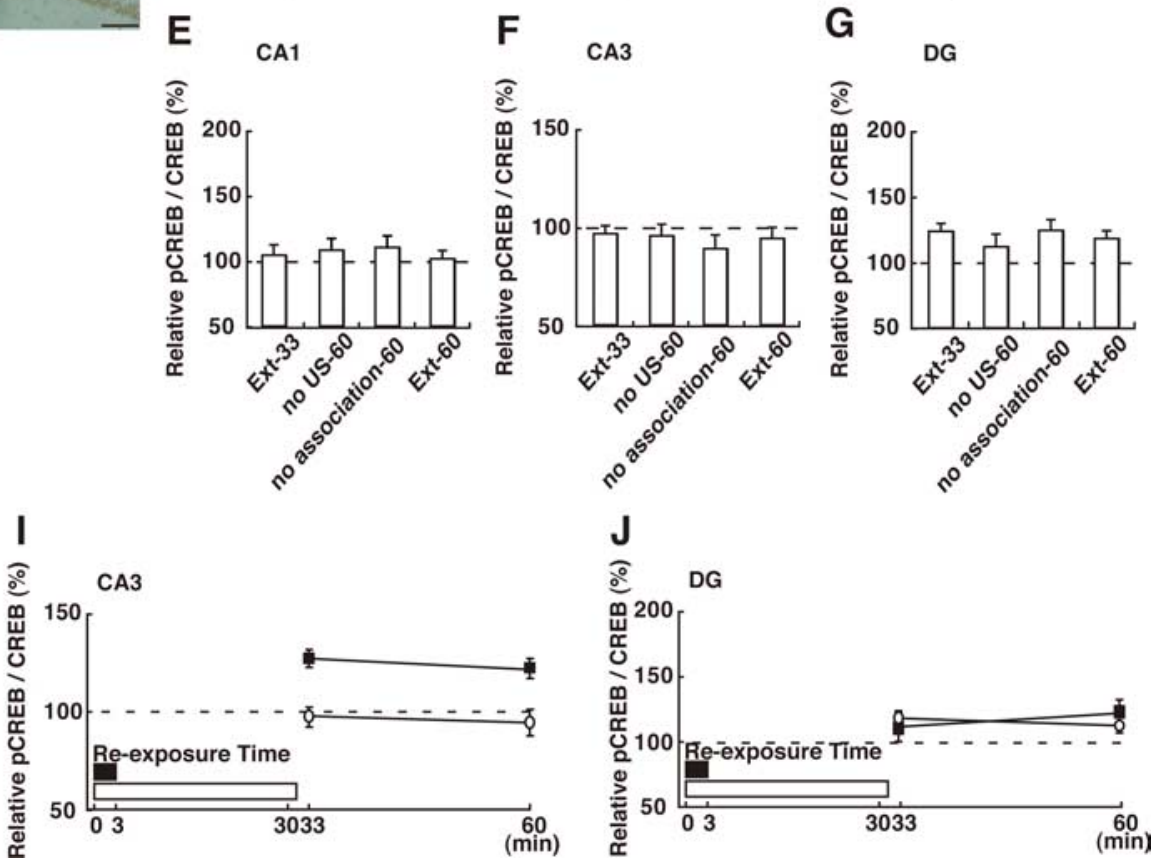

Figure 4. Effects of the reexposure duration on CREB activation in the hippocampus. $A$, Representative CA1 pCREB-positive cell immunohistochemistry obtained from indicated mice. Scare bar, $100 \mu \mathrm{m}$. $\boldsymbol{A}-\boldsymbol{D}$, Effects of the 3 min reexposure duration on CREB activation in CA1 (B), CA3 ( $\boldsymbol{C}$ and DG (D) regions of hippocampus (Recon-33, $n=11$; no US-33, $n=10$; no association-33, $n=9$; Recon-60, $n=9$ ). ${ }^{*} p<0.05$, compared with the unconditioned groups (no US-33 and no association-33). $\boldsymbol{E}-\boldsymbol{G}$, Effects of the 30 min reexposure duration on $(\mathrm{REB}$ activation in $C A 1(\boldsymbol{E})$, $\mathrm{CA} 3(\boldsymbol{F})$ and DG (G) regions of hippocampus (Ext-33, $n=10 ; n$ US $-60, n=15 ;$ no association-60, $n=14$; Ext-60, $n=17$ ). $\boldsymbol{H}$-J, Comparison of CREB activation after 3 and 30 min reexposure in CA1 (H), CA3 $(I)$, and DG $(J)$ regions of hippocampus in the conditioned group. Error bars are SEM. CREB activation was calculated by normalizing the number of pCREB-positive cells to the total CREB-positive cells. Data of CREB activation for each group were expressed as the percentage of the averaged values in the no US-33 control group.

reexposure versus time interactions (Fig. $3 F, G$ ) (reexposure vs time interaction; PL: $F_{(1,43)}=11.25, p<0.05 ;$ IL: $F_{(1,43)}=6.08$, $p<0.05)$. The post hoc Bonferroni's test showed significantly higher activation of CREB in the Ext-60 group compared with the other groups $(p<0.05)$, indicating that CREB was activated in both $\mathrm{mPFC}$ regions $30 \mathrm{~min}$ after the $30 \mathrm{~min}$ reexposure (Fig. $3 F, G)$. Thus, these observations indicate that CREB is activated in the PL and IL prefrontal regions when contextual fear memory is extinguished but not reconsolidated.

\section{Hippocampus}

We next analyzed the hippocampus. In contrast to the results for the $\mathrm{mPFC}$, hippocampal CREB is activated in the reconsolidation but not extinction phase. One-way ANOVA across the $3 \mathrm{~min}$ reexposure groups revealed significant effects of group in the CA1 and CA3 but not the dentate gyrus (DG) regions of the hippocampus (Fig. $4 B-D)\left(\mathrm{CA1}: F_{(3,35)}=4.74, p<0.05 ; \mathrm{CA} 3: F_{(3,35)}\right.$ $=9.25, p<0.05 ;$ DG: $\left.F_{(3,35)}=0.80, p>0.05\right)$. Post hoc analyses showed a significant higher level of pCREB in the CA1 and CA3 regions of the Recon-33 and Recon-60 groups compared with the other control groups $(p<0.05)$, indicating that CREB is activated in the hippocampal $\mathrm{CA} 1$ and $\mathrm{CA} 3$ regions of the conditioned groups after a 3 min reexposure (Fig. $4 B-D$ ). In contrast, no CREB activation was observed in these three regions of the hippocampus in the $30 \mathrm{~min}$ reexposure groups $\left(\mathrm{CA} 1: F_{(3,52)}=\right.$ $0.24, p>0.05$; CA3: $F_{(3,52)}=0.29, p>0.05$; DG: $F_{(3,52)}=0.52$, $p>0.05$ ), indicating that CREB is not activated in the hippocampus in the extinction phase (Fig. $4 E-G$ ). Consistent with this, a two-way ANOVA across the conditioned groups followed by the post hoc Bonferroni's test showed significantly higher activation of CREB in the CA1 and CA3 but not DG region of the Recon groups (Recon-33 and -60) compared with the Ext groups (Fig. $4 H-J$ ) (reexposure vs time interaction; CA1: $F_{(1,43)}=0.03, p>$ 0.05 ; CA3: $F_{(1,43)}=0.09, p>0.05 ;$ DG: $\left.F_{(1,43)}=0.82, p>0.05\right)$. These observations indicate that CREB is activated in the CA1 and $\mathrm{CA} 3$ regions of the hippocampus when contextual fear memory is reconsolidated but not extinguished. Additionally, it is important to point out that CREB activation was not observed in the hippocampus in the extinction phase, although contextual fear 
A

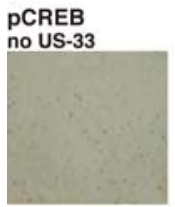

no US-60

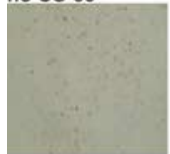

CREB

no US-33

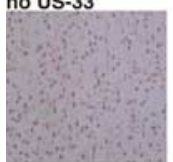

no US-60

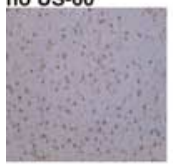

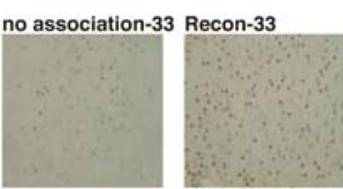

no association-60 Ext-33

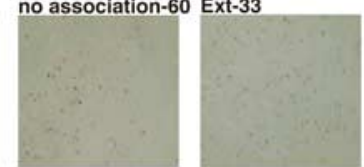

no association-33 Recon-33

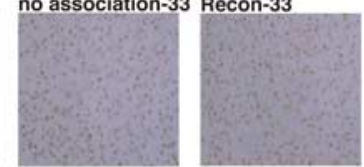

no association-60 Ext-33

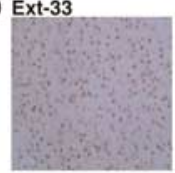

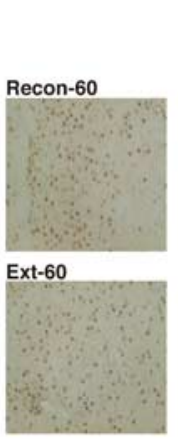

Recon-60

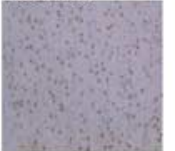

Ext-60

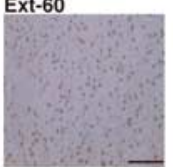

B
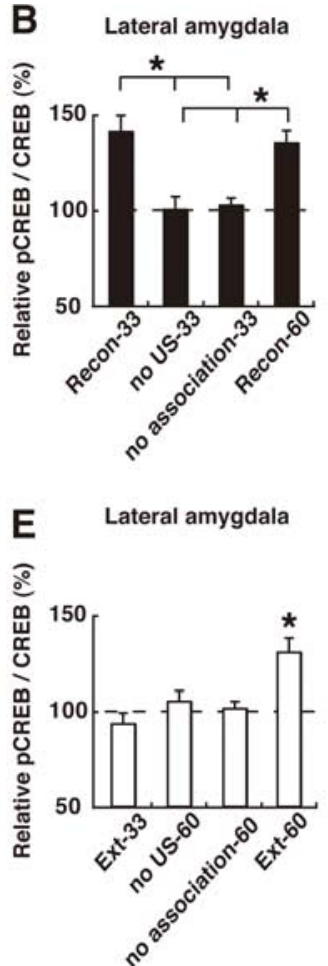

I

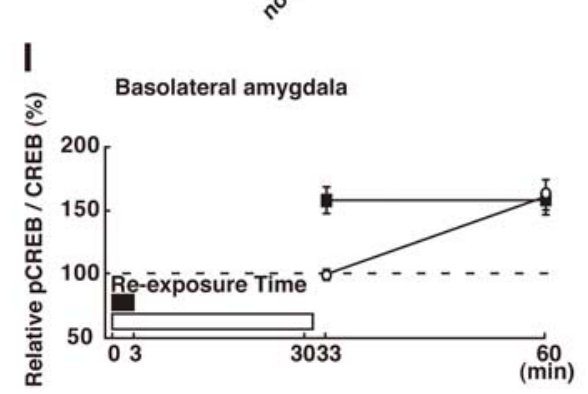

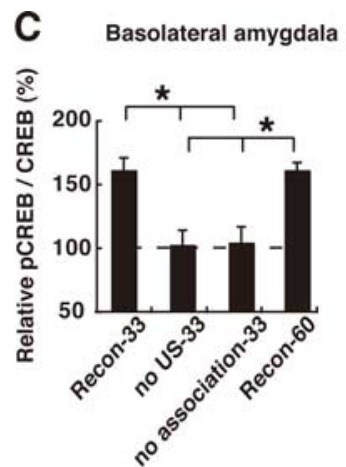
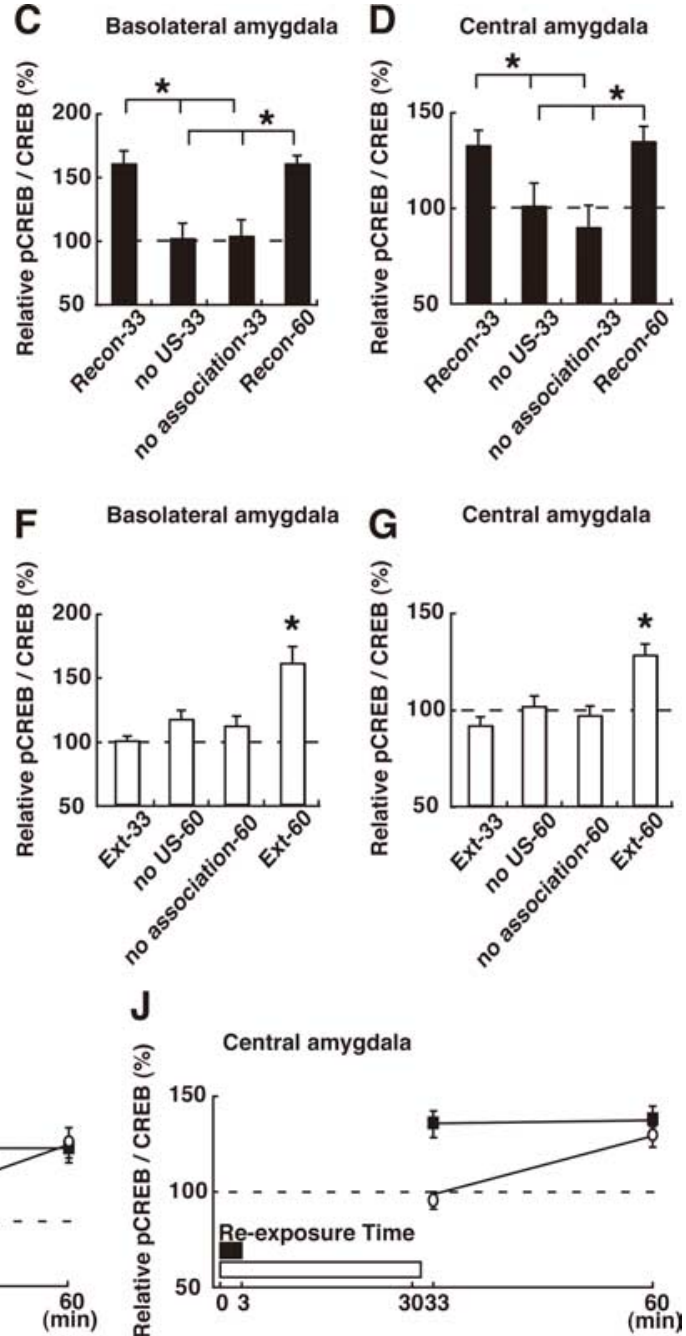

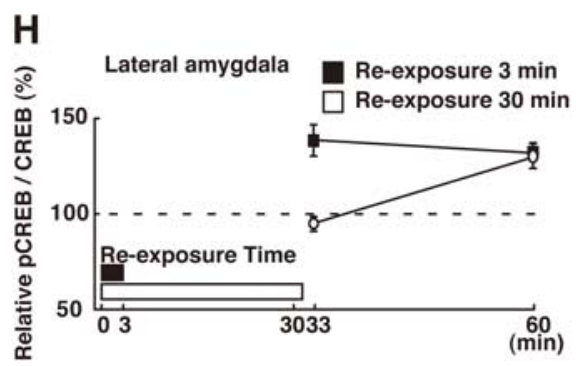

Figure 5. Effects of the reexposure duration on CREB activation in the amygdala. $A$, Representative BLA pCREB-positive cell immunohistochemistry obtained from indicated mice. Scare bar, 100 $\mu \mathrm{m} . \boldsymbol{B}-\boldsymbol{D}$, Effects of the 3 min reexposure duration on (REB activation in $L A(\boldsymbol{B}), B L A(\boldsymbol{C})$, and $C$ ( $(\boldsymbol{D})$ regions of amygdala (Recon-33, $n=11 ; n$ no US-33, $n=10 ;$ no association-33, $n=9 ;$ Recon-60, $n=9$ ). ${ }^{*} p<0.05$, compared with the unconditioned groups (no US-33 and no association-33). $\boldsymbol{E}-\boldsymbol{G}$, Effects of the 30 min reexposure duration on CREB activation in $L A(\boldsymbol{E})$, BLA $(\boldsymbol{F})$ and $C e(\boldsymbol{G})$ regions of amygdala (Ext-33, $n=10$; no US-60, $n=15$; no association-60, $n=14$; Ext-60, $n=17$ ). ${ }^{*} p<0.05$, compared with the other groups. $H-J$, Comparison of CREB activation after 3 and 30 min

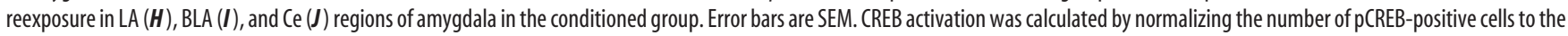
total CREB-positive cells. Data of CREB activation for each group were expressed as the percentage of the averaged values in the no US-33 control group.

memory was reactivated during the reexposure. This observation indicates that although short reexposure that triggers memory reconsolidation induces CREB activation in the hippocampus, this activation is suppressed when longer context reexposure that produces within-session extinction is used.

\section{Amygdala}

We finally analyzed the levels of pCREB in the amygdala. CREB was activated in the lateral (LA), basolateral (BLA), and central (Ce) regions of the amygdala in both the reconsolidation and extinction phases. One-way ANOVA across the $3 \mathrm{~min}$ or $30 \mathrm{~min}$ reexposure groups revealed significant effects of group in the three regions of the amygdala (Fig. $5 B-G)\left(\mathrm{LA}: 3 \mathrm{~min}, F_{(3,35)}=\right.$ 9.87, $p<0.05 ; 30 \mathrm{~min}, F_{(3,52)}=7.26, p<0.05$; BLA: 3 min, $F_{(3,35)}$ $=9.17, p<0.05 ; 30 \mathrm{~min}, F_{(3,52)}=7.20, p<0.05$; Ce: $3 \mathrm{~min}, F_{(3,35)}$ $\left.=4.80, p<0.05 ; 30 \mathrm{~min}, F_{(3,52)}=8.48, p<0.05\right)$. The level of pCREB was significantly increased in the three amygdaloid regions of the Recon-33, Recon-60, and Ext-60 groups compared with the other 3 or $30 \mathrm{~min}$, respectively, reexposure control groups (Fig. $5 B-G)(p>0.05)$. These results indicated that no
CREB activation was observed $3 \mathrm{~min}$ after the $30 \mathrm{~min}$ reexposure in the conditioned extinction groups. Consistent with this, a twoway ANOVA across the conditioned groups revealed significant reexposure versus time interactions in these three regions of the amygdala (Fig. $5 H-J$ ) (reexposure vs time interaction; LA: $F_{(1,43)}$ $=7.60, p<0.05$; BLA: $F_{(1,43)}=6.60, p<0.05$; Ce: $F_{(1,43)}=5.71$, $p<0.05)$. The post hoc Bonferroni's test showed that the pCREB levels were significantly increased in the three amygdaloid regions of the Recon-33, Recon-60, and Ext-60 groups compared with the Ext-33 group (Fig. 5H-J) $(p<0.05)$. Collectively, these observations indicate that CREB was activated in the amygdala when the fear memory was being reconsolidated and extinguished but showed a different time course from the beginning of the reexposure to the context between the reconsolidation and extinction phases. Extinction conditioned groups showed activation of CREB but also showed a delay of CREB activation compared with the reconsolidation group, although the contextual fear memory was reactivated in both groups. These differences in the time course of CREB activation between the reconsolidation 
A

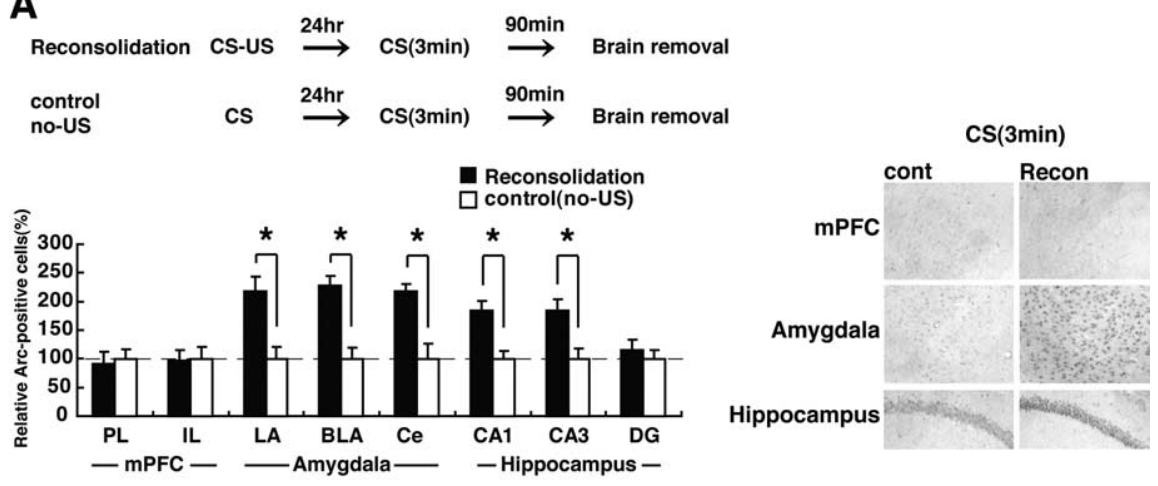

B

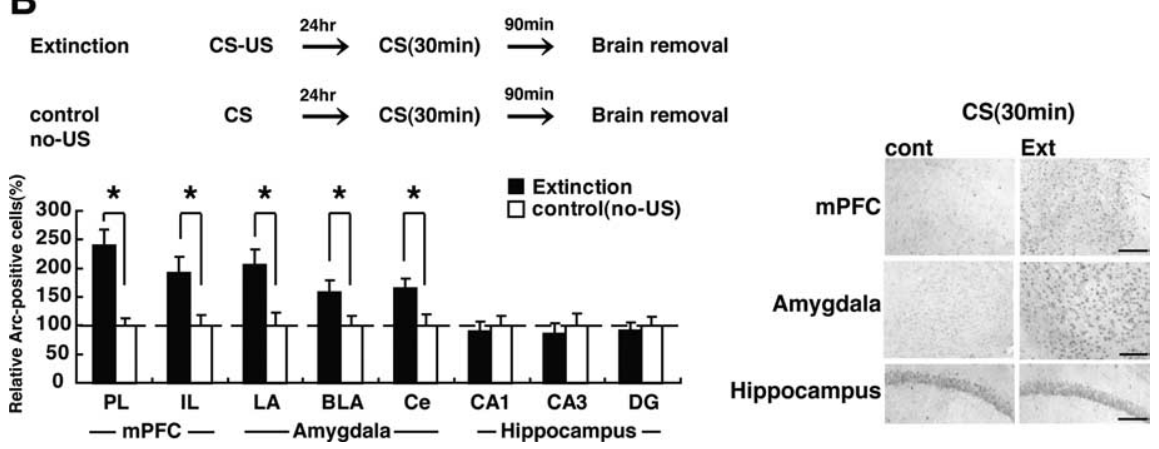

Figure 6. Effects of the duration of reexposure on Arc expression in the mPFC, amygdala, and hippocampus. $A, B$, Experimental design used with data presented below. $\boldsymbol{A}$, Effects of the 3 min reexposure duration on Arc expression in the mPFC, amygdala, and hippocampus (reconsolidation, $n=10$; control, $n=9$ ). ${ }^{*} p<0.05$, compared with the control group. $\boldsymbol{B}$, Effects of the $30 \mathrm{~min}$ reexposure duration on Arc expression in $\mathrm{mPFC}$, amygdala, and hippocampus (extinction, $n=11$; control, $n=11$ ). ${ }^{*} p<0.05$, compared with the control group. Error bars are SEM. Data of Arc expression for each group were expressed as the percentage of the averaged values in the control group. Scale bar, $100 \mu \mathrm{m}$.

and extinction groups indicates that CREB activation triggered by a $30 \mathrm{~min}$ reexposure is not simply attributable to the reactivation of the fear memory and, furthermore, that the mechanisms for the regulation of CREB activation differ in the reconsolidation and extinction phases.

As a control experiment, we examined CREB activation in the visual cortex. In contrast to the results in Figures 3-5, no CREB activation was observed in the conditioned groups after the 3 and $30 \mathrm{~min}$ reexposure (supplemental Fig. 1, available at www. jneurosci.org as supplemental material).

In summary, our anatomical analyses suggest that activation of CREB in the hippocampus and amygdala contributes to the reconsolidation of the contextual fear memory, whereas this activation in the amygdala and prefrontal cortex contributes to the extinction.

\section{Upregulation of Arc expression in distinct brain regions in the reconsolidation and extinction phases}

To ask whether the activation of CREB observed in Figures 3-5 are reflected by the expression of a CREB-target gene, we measured the expression of the immediate-early gene Arc in the reconsolidation and extinction phases. Arc is a CREB-dependent gene (Kawashima et al., 2008), the expression of which is regulated by neuronal activity. Previous studies have shown that it is upregulated after contextual fear memory formation and retrieval (Guzowski et al., 1999; Zhang et al., 2005; Kee et al., 2007). Mice were trained in the presence (conditioned group) or absence (unconditioned control group) of a single footshock and $24 \mathrm{~h}$ later were placed back in the training context for 3 or $30 \mathrm{~min}$.
Ninety minutes after the reexposure, mice were assessed for Arc expression using immunohistochemistry. After the $3 \mathrm{~min}$ reexposure, conditioned groups showed a significant upregulation of Arc expression in the CA1 and CA3 regions of the hippocampus and the LA, BLA, and Ce regions of the amygdala (Fig. 6A) (CA1: $F_{(1,17)}=13.80, p<0.05$; CA3: $F_{(1,17)}=$ $10.40, p<0.05$; LA: $F_{(1,17)}=12.16, p<$ 0.05; BLA: $F_{(1,17)}=14.95, p<0.05$; Ce: $\left.F_{(1,17)}=5.24, p<0.05\right)$. No changes were observed in the DG region of the hippocampus, nor in the PL and IL regions of the $\mathrm{mPFC}$ when compared with the unconditioned control groups (Fig. 6A) $\left(\mathrm{DG}: F_{(1,17)}=0.46, p>0.05\right.$; PL: $F_{(1,17)}=$ $0.07, p>0.05$; IL: $\left.F_{(1,17)}=0.01, p>0.05\right)$.

In contrast, after the $30 \mathrm{~min}$ reexposure, conditioned groups showed a significant upregulation of Arc expression in the two $\mathrm{MPFC}$ regions and the three amygdaloid regions, but not the three hippocampal regions, compared with the unconditioned control groups (Fig. $6 B$ ) (PL: $F_{(1,20)}$ $=16.56, p<0.05$; IL: $F_{(1,20)}=12.68, p<$ 0.05; LA: $F_{(1,20)}=25.41, p<0.05$; BLA: $F_{(1,20)}=12.81, p<0.05$; Ce: $F_{(1,20)}=4.43$, $p<0.05$; CA1: $F_{(1,20)}=0.01, p>0.05$; CA3: $F_{(1,20)}=0.03, p>0.05$; DG: $F_{(1,20)}=$ $0.01, p>0.05)$. These results are consistent with the observations in Figures 3-5 and indicate that the short reexposure that triggered reconsolidation induced CREBmediated gene expression in the amygdala/hippocampus, whereas the long reexposure that triggered extinction induced expression in the amygdala/mPFC. Furthermore, similar to the results of the CREB activation (Fig. 4), we found that hippocampal Arc is upregulated in the reconsolidation but not extinction phases, suggesting that these two processes may interact at the molecular level in the hippocampus.

\section{Roles of protein synthesis in the mPFC, hippocampus, and} amygdala in memory reconsolidation and extinction

The above analyses suggest that short context reexposure that triggers reconsolidation induces activation of CREB-mediated gene expression in the amygdala and hippocampus. In contrast, long context reexposure that triggers extinction induces CREB activation in the amygdala and mPFC (Figs. 3-5). These results raise the possibility that new gene expression in distinct brain regions is required for reconsolidation and extinction of contextual fear memory, respectively. To further test this possibility, we examined the effects of protein synthesis inhibition in the mPFC, amygdala, or hippocampus on reconsolidation and extinction of contextual fear memory. We performed a similar experiment as in Figure 1, except that WT mice received an infusion of the protein synthesis inhibitor ANI or VEH immediately after the 3 or $30 \mathrm{~min}$ reexposure to the context (Fig. $7 \mathrm{~A}$ ). Cannula tip placements are shown in the supplementary data, and only mice with cannula tips within the boundaries of the mPFC, hippocampus or amygdala were included in the data analysis (supplemental Fig. 2, available at www.jneurosci.org as supplemental material). During the 3 min reexposure, the $\mathrm{VEH}$ and ANI groups showed 


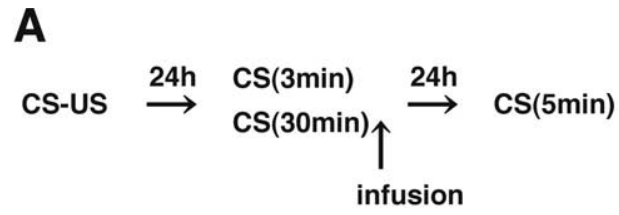

B
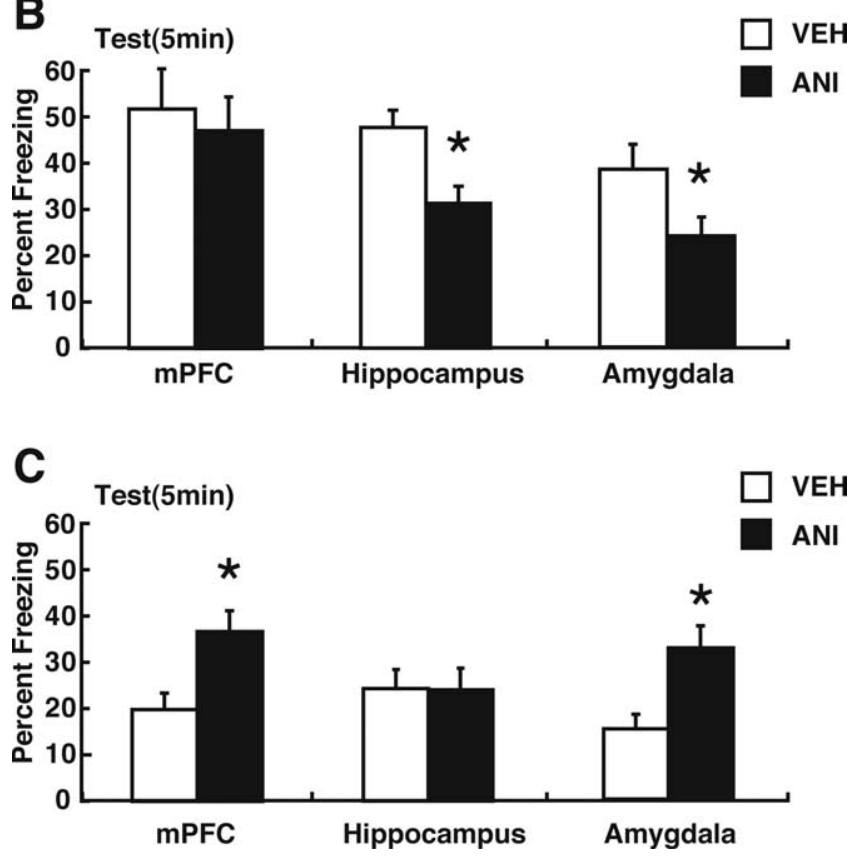

Figure 7. Effects of protein synthesis inhibition in the $\mathrm{PPFC}$, hippocampus, or amygdala on reconsolidation and extinction. $\boldsymbol{A}$, Experimental design used with data. Mice were infused VEH or ANI into the mPFC, hippocampus, or amygdala immediately after 3 or 30 min reexposure. $\boldsymbol{B}$, Effects of protein synthesis inhibition in $\mathrm{MPFC}$, hippocampus, or amygdala on reconsolidation. Freezing scores during the test session are shown (mPFC: VEH, $n=10 ; \mathrm{ANI}, n=11$; hippocampus: VEH, $n=12$; ANI, $n=12$; amygdala: VEH, $n=9$; ANI, $n=9$ ). C, Effects of protein synthesis inhibition in $\mathrm{mPFC}$, hippocampus, or amygdala on extinction. Freezing scores during test session are shown (mPFC: VEH, $n=9 ; \mathrm{ANI}, n=9$; hippocampus: VEH, $n=10 ; \mathrm{ANI}, n=10$; amygdala: VEH, $n=8 ; \mathrm{ANI}, n=9$ ). During reexposure, freezing scores in 5 min blocks are presented. Error bars are SEM. ${ }^{*} p<0.05$ versus VEH-treated groups.

comparable levels of freezing $(p>0.05)$. Infusion of ANI into the $\mathrm{mPFC}$ immediately after the $3 \mathrm{~min}$ reexposure did not alter the level of freezing tested $24 \mathrm{~h}$ later $\left(F_{(1,19)}=0.17 ; p>0.05\right)$; ANItreated mice exhibited comparable freezing levels compared with VEH-treated mice (Fig. $7 B$ ). In contrast, an infusion of ANI into the hippocampus or amygdala immediately after the 3 min reexposure impaired the expression of the contextual fear memory tested 24 h later (hippocampus: $F_{(1,23)}=13.84, p<0.05$; amygdala: $\left.F_{(1,16)}=5.32, p<0.05\right)$; ANI-treated mice exhibited significantly lower freezing levels compared with VEH-treated mice (Fig. $7 B)(p<0.05)$. These results are consistent with previous findings and confirmed that hippocampal protein synthesis is required for reconsolidation of the contextual fear memory (Debiec et al., 2002; Frankland et al., 2006; Suzuki et al., 2008). The novel result is that we found that reconsolidation of contextual fear memory requires new protein synthesis in the amygdala. Together with our anatomical analyses (Figs. 3-6), our results indicate that reconsolidation of contextual fear memory requires new gene expression in the hippocampus and amygdala but not in the $\mathrm{mPFC}$.

During the $30 \mathrm{~min}$ reexposure, comparable within-session extinction was observed between the VEH and ANI groups (mPFC: overall freezing, $F_{(1.80)}=3.56, p>0.05$; decrease over time, $F_{(5,80)}$
$=26.07, p<0.05$; hippocampus: overall freezing, $F_{(1.90)}=0.08$, $p>0.05$; decrease over time, $F_{(5,90)}=26.61, p<0.05$; amygdala: overall freezing, $F_{(1.75)}=0.43, p>0.05$; decrease over time, $F_{(5,75)}$ $=30.92, p<0.05)$. Measurements $24 \mathrm{~h}$ after this $30 \mathrm{~min}$ reexposure indicated that long-term extinction occurred in the VEHtreated mice (first $5 \mathrm{~min}$ in reexposure session vs test; $\mathrm{mPFC}$ : $t_{(16)}$ $=5.03, p<0.05$; hippocampus: $t_{(18)}=3.75, p<0.05$; amygdala: $\left.t_{(13)}=4.27, p<0.05\right)$. Infusion of ANI into the mPFC or amygdala immediately after the $30 \mathrm{~min}$ reexposure impaired the longterm extinction of the contextual fear memory tested $24 \mathrm{~h}$ later $\left(\mathrm{mPFC}: F_{(1,16)}=9.24, p<0.05\right.$; amygdala: $F_{(1,15)}=9.25, p<$ $0.05)$; ANI-treated mice exhibited significantly higher freezing levels compared with VEH-treated mice (Fig. 7C) $(p<0.05)$. In contrast, infusion of ANI into the hippocampus did not alter the level of freezing tested $24 \mathrm{~h}$ later $\left(F_{(1,18)}=0.08 ; p>0.05\right)$ (Fig. $7 C)$. These results indicated that protein synthesis in the $\mathrm{mPFC}$ and amygdala but not the hippocampus is required for long-term extinction of contextual fear memory.

Together, these observations support our results from the biochemical experiments that CREB-mediated gene expression is induced in distinct regions in the reconsolidation and extinction phases and suggest that the hippocampus, amygdala, and mPFC play distinct roles in the reconsolidation and extinction of the contextual fear memory through region-specific regulation of gene expression.

\section{Discussion}

Our previous behavioral studies demonstrated that memory reactivation triggers two processes: reconsolidation and extinction (Suzuki et al., 2004). These two processes have opposing actions on the fate of the retrieved memory: reconsolidation serves to stabilize or strengthen the memory, whereas extinction involves the formation of an inhibitory CS-no US association that competes with the original memory. Using a contextual fearconditioning paradigm, in the present study we first established that both these processes depend on CREB-mediated transcription (Fig. 1). Using immunohistochemical and targeted pharmacological approaches, our studies next indicated that these competing processes are supported by partially dissociable brain regions. After brief reactivation, new proteins are required in the hippocampus/amygdala for reconsolidation of contextual fear memories (Fig. $7 B$ ). In contrast, after prolonged reactivation, new proteins are required in the amygdala/mPFC for long-term extinction (Fig. 7C).

A critical biochemical feature of reconsolidation and longterm extinction of contextual fear memory is a requirement for gene expression (Suzuki et al., 2004). We previously demonstrated that CREB-mediated transcription is required for the reconsolidation of the contextual fear memory (Kida et al., 2002). In this study, genetic suppression of CREB function also blocked long-term extinction, indicating that long-term extinction undergoes a transcription-dependent process (Fig. 1C,D). To investigate the brain regions activated in the reconsolidation and extinction phases, we analyzed the brain regions where CREB is activated by measuring levels of pCREB after either brief ( $3 \mathrm{~min}$ ) or prolonged (30 $\mathrm{min}$ ) reexposure to the conditioning context. Furthermore, to determine whether our observations of CREB activation are reflected by the expression of CREB-dependent, neuronal activity-dependent genes, we measured the expression levels of Arc.

When a shorter context reexposure was used, we found that CREB-mediated gene expression (CREB phosphorylation and Arc induction) was induced in the CA1 and CA3 regions of the 
hippocampus and the LA, BLA, and Ce regions of the amygdala (Figs. 3-6). These data suggest that reconsolidation engages CREB-dependent processes in the hippocampus and amygdala (but not the mPFC). These observations are consistent with previous findings showing that retrieval of contextual fear memory induces c-fos and Zif268 expression in the CA1 of hippocampus but not the PL and IL of the mPFC (Frankland et al., 2004). Similarly, another study showed that this retrieval induces Zif268 expression in the LA, BLA, and Ce regions of the amygdala and the CA1 but not the DG of the hippocampus (Lee et al., 2001). Consistent with previous observations (Debiec et al., 2002; Suzuki et al., 2008), we showed that hippocampal inhibition of protein synthesis disrupts subsequent expression of the contextual fear memory (Fig. 7B). More importantly, we finally demonstrated that protein synthesis inhibition in the amygdala also disrupted the reactivated contextual fear memory (Fig. $7 B$ ). These observations indicate that reconsolidation of the contextual fear memory depends on new gene expression in the hippocampus and amygdala.

After prolonged reexposure to the context, we found that CREB-mediated gene expression was induced in the amygdala and the mPFC (Figs. 3, 5, 6). Consistent with these changes in CREB phosphorylation and Arc expression, we found that longterm extinction was blocked by protein synthesis inhibition in the mPFC and amygdala but not in the hippocampus (Fig. 7C). These observations suggested that long-term extinction of contextual fear memory depends on new gene expression in the mPFC and amygdala. Recent studies have shown that the amygdala plays a significant role in the acquisition of tone fear extinction, whereas the mPFC is implicated in its consolidation (Quirk et al., 2000; Santini et al., 2004). Indeed, consolidation of tone fear extinction requires protein synthesis and NMDA receptordependent bursting in the mPFC (Santini et al., 2004; BurgosRobles et al., 2007). Together with our findings, these data suggest that the amygdala and mPFC might play critical roles in the extinction of both contextual and tone fear memories.

Our observations that CREB activation and Arc expression are induced in the hippocampus/amygdala and amygdala/mPFC in the reconsolidation and extinction phases, respectively, indicates that gene expression is regulated in distinct ways after brief versus prolonged context reexposure (Figs. 3-6). In particular, these observations extend our previous behavioral observations that reexposure to the CS triggers two distinct time-dependent processes, reconsolidation and extinction, and indicate that reconsolidation and extinction are dissociable at the anatomical level.

Previous studies have established that protein synthesis inhibition after a brief reexposure to the CS disrupts the subsequent expression of the reactivated fear memory (Nader et al., 2000; Debiec et al., 2002; Kida et al., 2002). In contrast, blocking protein synthesis after prolonged reexposure blocks long-term extinction but does not disrupt the original fear memory (Eisenberg et al., 2003; Pedreira and Maldonado, 2003; Suzuki et al., 2004). Whereas it is not unexpected that new proteins are necessary for the formation of a long-term extinction memory (Santini et al., 2004), it is surprising that the original fear memory is left intact, although it has been reactivated under the condition in which protein synthesis was inhibited (Suzuki et al., 2004). This observation indicates that reconsolidation and extinction do not proceed independently (but see Duvarci et al., 2006). That is, these two processes must interact in some way.

Importantly, the present series of experiments identify the hippocampus and the amygdala as candidate anatomical loci for this interaction between the reconsolidation and extinction phases. First, we observed that CREB-mediated gene expression is induced in the hippocampus after short, but not longer, reexposure to the CS (Fig. 4). This suggests that gene expression in the hippocampus undergoes distinct regulation in the reconsolidation and extinction phases. Our observation that CREBmediated gene expression was not induced in the extinction phase even though contextual fear was reactivated indicates that such induction must be suppressed when within-session extinction occurs. Second, we observed differences in the time course of amygdaloid CREB activation in the reconsolidation and extinction phases (Fig. 5), indicating that amygdaloid CREB activation is differentially regulated in these two phases and, furthermore, that amygdaloid CREB activation observed in the extinction phase is not simply caused by fear memory reactivation. Furthermore, amygdaloid inhibition of protein synthesis after prolonged reexposure blocked long-term extinction without affecting the subsequent expression of the original fear memory, whereas this inhibition after brief reexposure disrupted the fear memory (Fig. 7). Therefore, we conclude that the interaction between the reconsolidation and extinction phases occurs in both the hippocampus and the amygdala at the molecular level. However, we cannot exclude another possibility: the CS onset initiates memory reactivation, but CS offset is the critical signal that determines the fate of memory by engaging reconsolidation or extinction processes (Pedreira et al., 2004, Pérez-Cuesta et al. 2007).

Our anatomical observations that acquisition of withinsession extinction of the contextual fear inhibited CREBmediated gene expression in the hippocampus corresponds with our behavioral observations that the acquisition of extinction prevents the disruption of the contextual fear memory by the inhibition of protein synthesis or CREB activity (Figs. 1, 7). Because previous studies demonstrated that destabilization and restabilization of reactivated contextual fear memories are hippocampus dependent (Debiec et al., 2002; Suzuki et al., 2008), it is possible that contextual fear extinction modulates the stability of the reactivated contextual fear memory by regulating hippocampal function. Therefore, it will be important to evaluate whether acquisition of contextual fear extinction prevents the destabilization of reactivated memory. A second possibility is that the originally contextual fear memory is destabilized and then restabilized (inactivated) in the extinction phase in a gene expression-independent manner (such as redistribution of preexisting proteins).

Restabilization of the reactivated contextual fear memory requires new gene expression in the hippocampus (Debiec et al., 2002). In contrast, we observed that inhibition of protein synthesis in the hippocampus did not affect long-term extinction (Fig. $7 C$ ), suggesting that the new protein synthesis in the hippocampus does not contribute to the consolidation of extinction memory. These contrasting observations indicate that the hippocampus plays distinct roles in reconsolidation and extinction of contextual fear memory. However, recent studies indicated critical roles of the hippocampus in the extinction of contextual fear. Indeed, cdk5 signaling, activation of the ubiquitin-proteasomal pathway, activation of $\mathrm{CB} 1$, and actin rearrangement in the hippocampus have been shown to be required for extinction of contextual fear memory (Fischer et al., 2004; Sananbenesi et al., 2007; de Oliveira Alvares et al., 2008; Lee et al., 2008). Therefore, it is possible that the hippocampus regulates contextual fear extinction through activation of these pathways without activating gene expression. Suppression of gene expression in the hippocampus might be a critical step that leads to long-term extinction. Addi- 
tional studies are required to investigate the regulatory roles of the hippocampus in memory extinction.

We observed that CREB activation and Arc expression were induced in the amygdala in both the reconsolidation and extinction phases (Figs. 5, 6). In agreement with this, previous studies demonstrated that extinction learning of tone fear induces expression of c-fos in the amygdala (Herry and Mons, 2004; Herry et al., 2008). However, a recent study demonstrated that retrieval of the contextual fear memory reactivates BLA neurons that are activated during contextual fear conditioning, whereas extinction learning prevents their activation (Reijmers et al., 2007). Together with these findings, our observation that the time course of amygdaloid CREB activation differs in the reconsolidation and extinction phases raises the possibility that distinct populations of amygdaloid neurons are activated in these phases. A recent study identified two distinct populations of BLA neurons (fear and extinction neurons), the activity of which is reversely correlated with low and high fear behavior (Herry et al., 2008). Therefore, it will be important to examine whether identical or different population of neurons are activated in the reconsolidation and extinction phases of contextual fear memory.

\section{References}

Anagnostaras SG, Gale GD, Fanselow MS (2001) Hippocampus and contextual fear conditioning: recent controversies and advances. Hippocampus 11:8-17.

Berman DE, Dudai Y (2001) Memory extinction, learning anew, and learning the new: dissociation in the molecular machinery of learning in cortex. Science 291:2417-2419.

Bito H, Deisseroth K, Tsien RW (1996) CREB phosphorylation and dephosphorylation: $\mathrm{a} \mathrm{Ca}^{2+}$ - and stimulus duration-dependent switch for hippocampal gene expression. Cell 87:1203-1214.

Burgos-Robles A, Vidal-Gonzalez I, Santini E, Quirk GJ (2007) Consolidation of fear extinction requires NMDA receptor-dependent bursting in the ventromedial prefrontal cortex. Neuron 53:871-880.

Davis HP, Squire LR (1984) Protein synthesis and memory. Psychol Bull 96:518-559.

Debiec J, LeDoux JE, Nader K (2002) Cellular and systems reconsolidation in the hippocampus. Neuron 36:527-538.

de Oliveira Alvares L, Pasqualini Genro B, Diehl F, Molina VA, Quillfeldt JA (2008) Opposite action of hippocampal CB1 receptors in memory reconsolidation and extinction. Neuroscience 154:1648-1655.

Duvarci J, Nader K (2004) Characterization of fear memory reconsolidation. J Neurosci 24:9269-9275.

Duvarci J, Mamou CB, Nader K (2006) Extinction is not a sufficient condition to prevent fear memories from undergoing reconsolidation in the basolateral amygdala. Eur J Neurosci 24:249-260.

Eisenberg M, Kobilo T, Berman DE, Dudai Y (2003) Stability of retrieved memory: inverse correlation with trace dominance. Science 301:1102-1104.

Fischer A, Sananbenesi F, Schrick C, Spiess J, Rdulovic J (2004) Distinct roles of hippocampal de novo protein synthesis and actin rearrangement in extinction of contextual fear. J Neurosci 24:1962-1966.

Flexner LB, Flexner JB, Stellar E (1965) Memory and cerebral protein synthesis in mice as affected by graded amounts of puromycin. Exp Neurol 13:264-272.

Frankland PW, Bontempi B, Talton LE, Kaczmarek L, Silva AJ (2004) The involvement of the anterior cingulated cortex in remote contextual fear memory. Science 304:881-883.

Frankland PW, Ding HK, Takahashi E, Suzuki A, Kida S, Silva AJ (2006) Stability of recent and remote contextual fear memory. Learn Mem 13:451-457.

Franklin KB, Paxinos G (1997) The mouse brain in stereotaxic coordinates. San Diego: Elesevier Academic.

Ginty DD, Bonni A, Greenberg ME (1994) Nerve growth factor activates a Ras-dependent protein kinase that stimulates $\mathrm{c}$-fos transcription via phosphorylation of CREB. Cell 77:713-725.

Gonzalez GA, Montminy MR (1989) Cyclic AMP stimulates somatostatin gene transcription by phosphorylation of CREB at serine 133. Cell 59:675-680.

Guzowski JF, McNaughton BL, Barnes CA, Worley PE (1999) Environment-specific expression of the immediate-early gene Arc in hippocampal neuronal ensembles. Nat Neurosci 2:1120-1124.

Hall J, Thomas KL, Everitt BJ (2001) Fear memory retrieval induces CREB phosphorylation and Fos expression within the amygdala. Eur J Neurosci 13:1453-1458.

Herry C, Mons N (2004) Resistance to extinction is associated with impaired immediate early gene induction in medial prefrontal cortex and amygdala. Eur J Neurosci 20:781-790.

Herry C, Ciocchi S, Senn V, Demmou L, Muller C, Luthi A (2008) Switching on and off fear by distinct neuronal circuits. Nature 454:600-606.

Kawashima T, Okuno H, Nonaka M, Adachi-Morishima A, Kyo N, Okamura M, Takemoto-Kimura S, Worley PF, Bito H (2008) A synaptic activityresponsive element in the Arc/Arg3.1 promoter essential for synapse-tonucleus signaling in activated neurons. Proc Natl Acad Sci U S A. Advance online publication. Retrieved December 31, 2008. doi:10.1073/ pnas. 0806518106.

Kee N, Teixeira CM, Wang AH, Frankland PW (2007) Preferential incorporation of adult-generated granule cells into spatial memory networks in the dentate gyrus. Nat Neurosci 10:355-362.

Kida S, Josselyn SA, deOrtiz SP, Kogan JH, Chevere I, Masushige S, Silva AJ (2002) CREB required for the stability of new and reactivated fear memories. Nat Neurosci 5:348-355.

Lee JL, Thomas KL, Everitt BJ (2001) Cellular imaging of zif268 expression in the hippocampus and amygdala during contextual and cued fear memory retrieval: selective activation of hippocampal CA1 neurons during the recall of contextual memories. J Neurosci 21:2186-2193.

Lee JL, Milton AL, Everitt BJ (2006) Reconsolidation and extinction of conditioned fear: inhibition and potentiation. J Neurosci 26:10051-10056.

Lee SH, Choi JH, Lee N, Lee HR, Kim JI, Yu NK, Choi SL, Lee SH, Kim H, Kaang BK (2008) Synaptic protein degradation underlies destabilization of retrieved fear memory. Science 319:1253-1256.

Lewis DJ (1979) Psychobiology of active and inactive memory. Psychol Bull 86:1054-1083.

Lu KT, Walker DL, Davis M (2001) Mitogen-activated protein kinase cascade in the basolateral nucleus of amygdala is involved in extinction of fear-potentiated startle. J Neurosci 21:RC162(1-5).

Mactutus CF, Riccio DC, Ferek JM (1979) Retrograde amnesia for old (reactivated) memory: some anomalous characteristics. Science 204:1319-1320.

Mayr B, Montminy M (2001) Transcriptional regulation by the phosphorylation-dependent factor CREB. Nat Rev Mol Cell Biol 2:599-609.

McGaugh JL (2000) Memory-a century of consolidation. Science 287:248-251.

Misanin JR, Miller RR, Lewis DJ (1968) Retrograde amnesia produced by electroconvulsive shock after reactivation of a consolidated memory trace. Science 160:554-555.

Morgan MA, LeDoux JE (1995) Differential contribution of dorsal and ventral medial prefrontal cortex to the acquisition and extinction of conditioned fear in rats. Behav Neurosci 109:681-688.

Morgan MA, LeDoux JE (1999) Contribution of ventrolateral prefrontal cortex to the acquisition and extinction of conditioned fear in rats. Neurobiol Learn Mem 72:244-251.

Morgan MA, Romanski LM, LeDoux JE (1993) Extinction of emotional learning: contribution of medial prefrontal cortex. Neurosci Lett 163:109-113.

Morrow BA, Elsworth JD, Rasmusson AM, Roth RH (1999) The role of mesoprefrontal dopamine neurons in the acquisition and expression of conditioned fear in the rat. Neuroscience 92:553-564.

Myers KM, Davis M (2002) Behavioral and neural analysis of extinction. Neuron 36:567-584.

Myers KM, Davis M (2007) Mechanisms of fear extinction. Mol Psychiatry $12: 120-150$.

Nader K, Schafe GE, LeDoux JE (2000) Fear memories require protein synthesis in the amygdala for reconsolidation after retrieval. Nature 406:722-726.

Pavlov IP (1927) Conditioned reflexes. London: Oxford UP.

Pedreira ME, Maldonado H (2003) Protein synthesis subserves reconsolidation or extinction depending on reminder duration. Neuron 38:863-869. 
Pedreira ME, Pérez-Cuesta LM, Maldonado H (2004) Mismatch between what is expected and what actually occurs triggers memory reconsolidation or extinction. Learn Mem 11:579-585.

Pérez-Cuesta LM, Hepp Y, Pedreira ME, Maldonado H (2007) Memory is not extinguished along with CS presentation but within a few seconds after CS-offset. Learn Mem 14:101-108.

Przybyslawski J, Sara SJ (1997) Reconsolidation of memory after its reactivation. Behav Brain Res 84:241-246.

Quirk GJ, Russo GK, Barron JL, Lebron K (2000) The role of ventromedial prefrontal cortex in the recovery of extinguished fear. J Neurosci 20:6225-6231.

Quirk GJ, Gracia R, Gonzalez-Lima F (2006) Prefrontal mechanisms in extinction of conditioned fear. Biol Psychiatry 60:337-343.

Reijmers LG, Perkins BL, Matsuo N, Mayford M (2007) Localization of a stable neuronal correlate of associative memory. Science 317:1230-1233.

Rescorla RA (2001) Experimental extinction. In: Handbook of contemporary learning theories (Mowrer RR, Klein S, eds), pp 119-154. Mahwah, NJ: Erlbaum.

Rosenblum K, Meiri N, Dudai Y (1993) Taste memory: the role of protein synthesis in gustatory cortex. Behav Neural Biol 59:49-56.

Sananbenesi F, Fischer A, Wang X, Schrick C, Neve R, Radulovic J, Tsai LH (2007) A hippocampal Cdk5 pathway regulates extinction of contextual fear. Nat Neurosci 10:1012-1019.

Santini E, Ge H, Ren K, deOrtiz SP, Quirk GJ (2004) Consolidation of fear extinction reuires protein synthesis in the medial prefrontal cortex. J Neurosci 24:5704-5710.

Sara SJ (2000) Retrieval and reconsolidation: toward a neurobiology of remembering. Learn Mem 7:73-84.

Schneider AM, Sherman W (1968) Amnesia: a function of the temporal relation of footshock to electroconvulsive shock. Science 159:219-221.

Shaywitz AJ, Greenberg ME (1999) CREB: a stimulus-induced transcription factor activated by a diverse array of extracellular signals. Annu Rev Biochem 68:821-861.

Silva AJ, Kogan JH, Frankland PW, Kida S (1998) CREB and memory. Annu Rev Neurosci 21:127-148.

Suzuki A, Josselyn SA, Frankland PW, Masushige S, Silva AJ, Kida S (2004) Memory reconsolidation and extinction have distinct temporal and biochemical signatures. J Neurosci 24:4787-4795.

Suzuki A, Mukawa T, Tsukagoshi A, Frankland PW, Kida S (2008) Activation of LVGCCs and CB1 receptors required for destabilization of reactivated contextual fear memories. Learn Mem 15:426-433.

Taubenfeld SM, Milekic MH, Monti B, Alberini CM (2001) The consolidation of new but not reactivated memory requires hippocampal C/EBPbeta. Nat Neurosci 4:813-818.

Tronel S, Milekic MH, Alberini CM (2005) Linking new information to a reactivated memory requires consolidation and not reconsolidation mechanisms. PLoS Biol 3:1630-1638.

Vianna MR, Szapiro G, McGaugh JL, Medina JH, Izquierdo I (2001) Retrieval of memory for fear-motivated training initiates extinction requiring protein synthesis in the rat hippocampus. Proc Natl Acad Sci U S A 98:12251-12254.

Viola H, Furman M, Izquierdo LA, Alonso M, Barros DM, de Souza MM, Izquierdo I, Medina JH (2000) Phosphorylated cAMP response element-binding protein as a marker of memory processing in rat hippocampus: effect of novelty. J Neurosci 20:RC112(1-5).

Walker DL, Ressler KJ, Lu KT, Davis M (2002) Facilitation of conditioned fear extinction by systemic administration or intra-amygdala infusions of D-cycloserine as assessed with fear-potentiated startle in rats. J Neurosci 22:2343-2351.

Zhang WP, Guzowski JF, Thomas SA (2005) Mapping neuronal activation and the influence of adrenergic signal during contextual memory retrieval. Learn Mem 12:239-247. 